\title{
Dynamic neuroplasticity and the automation of motivated behavior
}

\author{
Brandon J. Aragona and Regina M. Carelli ${ }^{1}$ \\ Department of Psychology, The University of North Carolina at Chapel Hill, Chapel Hill, North Carolina 27599-3270, USA
}

Extraordinary behavioral flexibility is necessary in order to meet energy needs. An animal must know when and where to search for food, guard itself and its offspring against predators, and continuously adjust foraging behavior as the changing environment dictates. These pressures have selected for the ability to accomplish numerous functions simultaneously. This is particularly necessary during the execution of motivated behaviors (behaviors that have initiation, procurement, and consummatory phases) (Swanson 2000), and is facilitated by habitual performance. Specifically, while motivated learning initially requires significant cognitive effort, with practice, complex tasks can be performed quite automatically. In a recent study, Hernandez et al. (2006) examined the neurobiology of this transition, from early learning to automatic responding, based on the hypothesis that the transition is mediated by plasticity within neural circuitry regulating motivated learning.

Hernandez et al. assessed neural plasticity anatomically using in situ hybridization to measure changes in the expression of two immediate early genes important for learning and memory: Zif268 and Homer 1a. Zif268 is a transcription factor involved in cellular and behavioral assays of learning (Knapska and Kaczmarek 2004). Homer $1 a$ is a component of the postsynaptic density of glutamate synapses (de Bartolomeis and Iasevoli 2003). This is especially important given the role played by glutamate transmission in learning (Gubellini et al. 2004; Kelley 2004). In addition to a general involvement in learning and memory, Zif268 and Homer 1a are also specifically important for motivated learning (Thomas et al. 2003; Lominac et al. 2005; Petrovich et al. 2005; Szumlinski et al. 2006). These genes were therefore chosen to examine whether plasticity within motivational brain circuitry is associated with the transition from initial motivated responding to automatic responding.

Rats learned an operant task where lever presses produced sugar pellets. In one group, gene expression was measured after several days of training, in which behavior was reliable but responding had not reached its maximum. These subjects were referred to as "early learners." In a separate group, gene expression was measured several weeks later, well after the behavioral measure had reached its maximum level, and these subjects were referred to as "overtrained." Control subjects were exposed to the same conditions; however, lever pressing had no programmed consequences. Relative to controls, early learners showed significantly higher expression levels of Zif268 and Homer 1a in several frontal cortical regions (including anterior cingulate, orbitofrontal, and prefrontal). In contrast with the early learners, overtrained subjects had significantly lower Homer $1 a$ expression in these cortical regions compared with controls (there was no difference for Zif268). This reversal was only found in the frontal cortex and not in other areas where gene expression was elevated in early learners, such as the dorsomedial striatum, hippocam-

\section{'Corresponding author.}

E-mail rcarelli@unc.edu; fax (919) 962-2537.

Article is online at http://www.learnmem.org/cgi/doi/10.1101//m.398806. pus, or sensory and motor cortex. These findings suggest decreased cortical influence during automatic responding.

Hernandez et al. (2006) then directly compared levels of gene expression in overtrained subjects to early learners. Overtrained rats had significantly higher Homer $1 a$ expression in the ventrolateral striatum compared to early learners. Further, there was a positive correlation between the number of lever presses and Homer $1 a$ expression in the ventrolateral striatum. These findings suggest that this specific portion of the striatum plays an important role in automation of behavior. And together, data presented in Hernandez et al. suggest a "dynamic shift" in the expression of plasticity-related immediate early gene expression, in which there is decreased cortical and increased striatal activity as a specific motivated output becomes very well established.

Importantly, this "cortex to striatum" shift may be unique to motivational learning, as a fundamentally distinct mechanism has been identified for spatial and contextual memory storage. Several recent studies have used similar neuroanatomical methods, as used by Hernandez et al. (2006) to convincingly demonstrate that recent spatial memories involve processing within the hippocampus, whereas remote spatial memories $(\sim 30 \mathrm{~d}$ after learning) require cortical processing (Frankland et al. 2004; Maviel et al. 2004; Frankland and Bontempi 2005). These studies demonstrate differential neural regulation of learning and memory depending on the behavior being examined.

Dynamic neuroplasticity mediating transitions from early learning to automatic responding is important for understanding the evolution of motivated behavior. Approach and avoidance behaviors (Adler 1966; Zhang et al. 2005), as well as operant learning (Brembs 2003; Hawkins et al. 2006), are ancient processes predating neocortex. For food seeking in mammals, the ability to distinguish between positive and negative valence is processed in phylogenetically older brain regions in the mid- and hindbrain (Grill and Norgren 1978), areas expressing very low levels of plasticity-related genes (Kelley 2004). However, these regions are highly interconnected to the more phylogenetically recent structures, such as neocortex and subcortical forebrain structures like the striatum. These regions possess the neuroplastic capabilities to efficiently meet energy needs by orchestrating the appropriate influence over hard-wired feeding areas, depending on level of experience of a particular motivated output. Specifically, with practice a complex behavior can be executed with only a minimal burden of awareness, because it is under striatal regulation. This leaves the cortex free to process additional features of the foraging experience, such as sensing danger or changes in the environment that may signal more promising foraging opportunities. If true, such shifts in corticostriatal regulation of motivated behavior can explain the adaptive benefit of habitual behavior.

Perhaps the most significant aspect of highly plastic capabilities of the coritcostriatal system mediating motivated learning is that this system is extremely sensitive to drugs of abuse (Nestler 2004). Drug addiction is widely conceptualized as a disorder of learning and memory (Di Chiara 1999; Hyman 2005), and increasing evidence suggests that compulsive drug seeking is 
associated with restructuring of corticostriatal circuitry (Kelley 2004; Everitt and Robbins 2005). Drug-induced plasticity is particularly strong in dopamine-containing neurons that project to this system (Ungless et al. 2001), and cocaine self-administration results in a significant reorganization of the striatum (Porrino et al. 2004). Initial drug taking affects the ventral striatum, whereas extensive drug intake is associated with alterations of the dorsal striatum (Porrino et al. 2004). This progression is consistent with pharmacological manipulations of drug seeking which show that signaling within the ventral striatum, in particular the nucleus accumbens, mediates the initial reward value of drug selfadministration (Maldonado et al. 1993). However, the nucleus accumbens has less influence over compulsive drug seeking, which is more strongly regulated by the dorsal striatum (Vanderschuren and Everitt 2005). Commonalities between transitions toward dorsal striatal regulation of compulsive drug seeking and increased striatal influence over habitually seeking natural rewards speaks to the nature of addiction. Specifically, drugs of abuse dominate behavior by targeting circuitry evolved to mediate highly flexible, plasticity-meditated, motivated learning. Importantly, a complete "takeover" of this system does not occur, as it would greatly impair fitness. At the cellular level, drugs leave distinct microcircuitry intact, allowing for continued seeking of natural rewards (Carelli et al. 2000; Carelli and Wondolowski 2003; Carelli and Wightman 2004), while otherwise exerting a disproportionate usurpation over motivated behaviors. Therefore, the coriticostriatal system is adaptive because of the flexibility described by Hernandez et al. (2006), but when this system is targeted by drugs, it may result in the inflexible compulsive drug seeking that defines addiction.

In conclusion, the recent study by Hernandez et al. (2006) describes a unique shift from cortical to striatal regulation of well-established motivated learning. While there appears to be adaptive advantages for decreased cognitive requirements during well-established behaviors, this novel finding provides a sobering example of why drug addiction is such a potent disorder. Moreover, there is increasing evidence that similar mechanisms may generalize across compulsive disorders, including gambling and obesity (Reuter et al. 2005; Volkow and Wise 2005). Therefore, while the brain has remarkable mechanisms to achieve complex behavioral execution with minimal cortical influence, unnatural activation of these systems is associated with maladaptive compulsions, especially our addictions.

\section{References}

Adler, J. 1966. Chemotaxis in bacteria. Science 153: 708-716. Brembs, B. 2003. Operant conditioning in invertebrates. Curr. Opin. Neurobiol. 13: 710-717.

Carelli, R.M. and Wightman, R.M. 2004. Functional microcircuitry in the accumbens underlying drug addiction: Insights from real-time signaling during behavior. Curr. Opin. Neurobiol. 14: 763-768.

Carelli, R.M. and Wondolowski, J. 2003. Selective encoding of cocaine versus natural rewards by nucleus accumbens neurons is not related to chronic drug exposure. J. Neurosci. 23: 11214-11223.

Carelli, R.M., Ijames, S.G., and Crumling, A.J. 2000. Evidence that separate neural circuits in the nucleus accumbens encode cocaine versus "natural" (water and food) reward. J. Neurosci. 20: 4255-4266.

de Bartolomeis, A. and Iasevoli, F. 2003. The Homer family and the signal transduction system at glutamatergic postsynaptic density: Potential role in behavior and pharmacotherapy. Psychopharmacol. Bull. 37: 51-83.
Di Chiara, G. 1999. Drug addiction as dopamine-dependent associative learning disorder. Eur. J. Pharmacol. 375: 13-30.

Everitt, B.J. and Robbins, T.W. 2005. Neural systems of reinforcement for drug addiction: From actions to habits to compulsion. Nat. Neurosci. 8: 1481-1489.

Frankland, P.W. and Bontempi, B. 2005. The organization of recent and remote memories. Nat. Rev. Neurosci. 6: 119-130.

Frankland, P.W., Bontempi, B., Talton, L.E., Kaczmarek, L., and Silva, A.J. 2004. The involvement of the anterior cingulate cortex in remote contextual fear memory. Science 304: 881-883.

Grill, H.J. and Norgren, R. 1978. Chronically decerebrate rats demonstrate satiation but not bait shyness. Science 201: 267-269.

Gubellini, P., Pisani, A., Centonze, D., Bernardi, G., and Calabresi, P. 2004. Metabotropic glutamate receptors and striatal synaptic plasticity: Implications for neurological diseases. Prog. Neurobiol. 74: $271-300$.

Hawkins, R.D., Clark, G.A., and Kandel, E.R. 2006. Operant conditioning of gill withdrawal in Aplysia. J. Neurosci. 26: $2443-2448$.

Hernandez, P.J., Schiltz, C.A., and Kelley, A.E. 2006. Dynamic shifts in corticostriatal expression patterns of the immediate early genes Homer $1 a$ and Zif268 during early and late phases of instrumental training. Learn. Mem. (this issue).

Hyman, S.E. 2005. Addiction: A disease of learning and memory. Am. J. Psychiatry 162: 1414-1422.

Kelley, A.E. 2004. Memory and addiction: Shared neural circuitry and molecular mechanisms. Neuron 44: 161-179.

Knapska, E. and Kaczmarek, L. 2004. A gene for neuronal plasticity in the mammalian brain: Zif268/Egr-1/NGFI-A/Krox-24/TIS8/ZENK? Prog. Neurobiol. 74: 183-211.

Lominac, K.D., Oleson, E.B., Pava, M., Klugmann, M., Schwarz, M.K., Seeburg, P.H., During, M.J., Worley, P.F., Kalivas, P.W., and Szumlinski, K.K. 2005. Distinct roles for different Homer1 isoforms in behaviors and associated prefrontal cortex function. J. Neurosci. 25: 11586-11594.

Maldonado, R., Robledo, P., Chover, A.J., Caine, S.B., and Koob, G.F. 1993. D1 dopamine receptors in the nucleus accumbens modulate cocaine self-administration in the rat. Pharmacol. Biochem. Behav. 45: 239-242.

Maviel, T., Durkin, T.P., Menzaghi, F., and Bontempi, B. 2004. Sites of neocortical reorganization critical for remote spatial memory. Science 305: 96-99.

Nestler, E.J. 2004. Historical review: Molecular and cellular mechanisms of opiate and cocaine addiction. Trends Pharmacol. Sci. 25: 210-218.

Petrovich, G.D., Holland, P.C., and Gallagher, M. 2005. Amygdalar and prefrontal pathways to the lateral hypothalamus are activated by a learned cue that stimulates eating. J. Neurosci. 25: 8295-8302.

Porrino, L.J., Lyons, D., Smith, H.R., Daunais, J.B., and Nader, M.A 2004. Cocaine self-administration produces a progressive involvement of limbic, association, and sensorimotor striatal domains. J. Neurosci. 24: 3554-3562.

Reuter, J., Raedler, T., Rose, M., Hand, I., Glascher, J., and Buchel, C. 2005. Pathological gambling is linked to reduced activation of the mesolimbic reward system. Nat. Neurosci. 8: 147-148.

Swanson, L.W. 2000. Cerebral hemisphere regulation of motivated behavior(1). Brain Res. 886: 113-164.

Szumlinski, K.K., Kalivas, P.W., and Worley, P.F. 2006. Homer proteins: Implications for neuropsychiatric disorders. Curr. Opin. Neurobiol. 16: 251-257.

Thomas, K.L., Arroyo, M., and Everitt, B.J. 2003. Induction of the learning and plasticity-associated gene Zif268 following exposure to a discrete cocaine-associated stimulus. Eur. J. Neurosci. 17: 1964-1972.

Ungless, M.A., Whistler, J.L., Malenka, R.C., and Bonci, A. 2001. Single cocaine exposure in vivo induces long-term potentiation in dopamine neurons. Nature 411: 583-587.

Vanderschuren, L.J. and Everitt, B.J. 2005. Behavioral and neural mechanisms of compulsive drug seeking. Eur. J. Pharmacol. 526: $77-88$.

Volkow, N.D. and Wise, R.A. 2005. How can drug addiction help us understand obesity? Nat. Neurosci. 8: 555-560.

Zhang, Y., Lu, H., and Bargmann, C.I. 2005. Pathogenic bacteria induce aversive olfactory learning in Caenorhabditis elegans. Nature 438: $179-184$ 


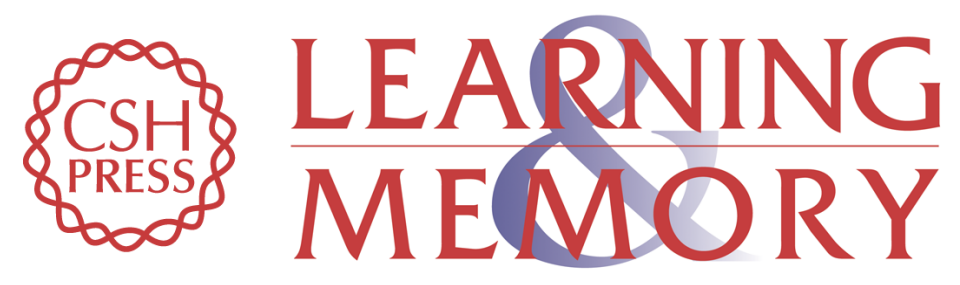

\section{Dynamic neuroplasticity and the automation of motivated behavior}

Brandon J. Aragona and Regina M. Carelli

Learn. Mem. 2006, 13:

Access the most recent version at doi:10.1101//m.398806

Related Content Dynamic shifts in corticostriatal expression patterns of the immediate early genes Homer 1a and Zif268 during early and late phases of instrumental

training

Pepe J. Hernandez, Craig A. Schiltz and Ann E. Kelley

Learn. Mem. UNKNOWN, 2006 13: 599-608

References This article cites 30 articles, 10 of which can be accessed free at: http://learnmem.cshlp.org/content/13/5/558.full.html\#ref-list-1

Articles cited in:

http://learnmem.cshlp.org/content/13/5/558.full.html\#related-urls

License

Email Alerting Receive free email alerts when new articles cite this article - sign up in the box at the Service top right corner of the article or click here. 